\title{
Master’s Degree In Management Information Systems With A Supply Chain Management Focus
}

Kizhanatham V. Ramaswamy, (E-mail: ramaswamy_kv@tsu.edu), Texas Southern University Joseph L. Boyd, Texas Southern University

Mayur Desai, Texas Southern University

\begin{abstract}
A graduate curriculum in Management Information Systems with a Supply Chain Management focus is presented. The motivation for this endeavor stems from the fact that the global scope of modern business organizations and the competitive environment in which they operate, requires an information system leveraged supply chain management system (SCM) to ensure the efficient delivery of the right product, at the right place, at the right time, in the right quantity, and at a competitive price to the customer.
\end{abstract}

\section{INTRODUCTION}<smiles>[CH]C1C=CCC=C1</smiles>

t has been reported that every year more than $\$ 1500$ billion of materials are purchased by manufacturing firms and the expenditure for purchases of materials and services at federal, state and local governments is of the order of $\$ 1000$ billions[1]. According to Chopra and Meindl [2] a supply chain consists of all parties involved, directly or indirectly, in fulfilling a customer request for a product or service. Van der Zee and Van der Vorst [3] define supply chain management "as the integrated planning, coordination, and control of all logistic business processes and activities in the supply chain to deliver superior customer value at less cost to the supply chain as a whole while satisfying requirements of other stakeholders in the supply chain". Vakharia[4] gives the following perspective for supply chain management: "SCM is the art and science of creating and accentuating synergistic relationships among the trading partners in supply and distribution channels with the common shared objective of delivering products and services to the right customer, in the right quantity, and at the right time”. According to Hausman [5] SCM is one of the leading edge strategies for business process reengineering, cost saving, and revenue enhancement today. SCM curriculum continues to be incorporated in business school programs in recent years at a fast pace.

Computer-Based Management Information Systems (MIS) have become indispensable for performing the management functions of planning, organizing, staffing, and controlling in small to multi-national business organizations. MIS is also widely used in government and other non-profit organizations. These systems have been leveraged by management to improve operational efficiency and productivity in many areas of the organization. These systems are so prevalent these days that they are now looked upon as an essential infrastructure of modern business organizations.

The global scope of modern business organizations and the competitive environment in which they operate, requires an information system leveraged supply chain management system (SCM) to ensure the efficient delivery of the right product, at the right place, at the right time, in the right quantity, and at a competitive price to the customer. The supply chain is comprised of suppliers/vendors, manufacturers, distributors, and retailers whose activities are coordinated through transportation, information flows, and financial infrastructure. Management's objective is to add value to the product or service by focusing on activities along the supply chain. In the following sections details of the graduate curriculum, MS in MIS is presented. 


\section{PROGRAM DESCRIPTION}

A. Educational Objectives

1. Provide basic foundation in Business Administration.

2. Develop required skills in using computers, popular business software and their applications to business.

3. Develop skills required for analysis and determination of information requirements, and for developing Management Information Systems using commercially available application generators and packages.

2. Develop a good understanding of Supply Chain functions and selected MIS applications in this area.

3. Provide students with the skills required to become knowledgeable users of at least one commercially available and popular MIS application with SCM focus.

4. Prepare students for managerial positions in the MIS/Supply Chain Management area of Construction, Manufacturing, Wholesale/Retail, Energy and Healthcare industries.

B. Admission Standards

1. Applicants to the graduate program in MIS will meet the general admission requirements and application process of the Graduate School.

2. All applicants must hold at least a Bachelor's degree in any discipline from an accredited university with an acceptable GPA.

3. Applicants must submit a satisfactory GMAT score taken within the last five (5) years.

C. Degree Requirements

Pre-Requisites: All applicants must have completed the following 24 credit hours of undergraduate business core courses at Texas Southern University or their equivalent elsewhere:

\begin{tabular}{|l|l|c|l|}
\hline Course & Description & Credit Hours & Department \\
\hline ACCT 231 & Principles of Accounting I & 3 & Accounting \& Finance \\
\hline ECON 231 & Principles of Economics I & 3 & History, Geography \& Economics \\
or ECON 232 & Principles of Economics II & 3 & \\
\hline FIN 301 & Basic Financial Management & 3 & Accounting \& Finance \\
\hline MGMT 300 & Principles of Management & 3 & Business Administration \\
MGSC 239 & Business Statistics I & 3 & \\
MGSC 302 & Production Management I & & \\
MGSC 304 & Management Information Systems & 3 & \\
MKTG 306 & Principles of Marketing & 3 & \\
\hline
\end{tabular}

Note: Above will constitute the basic business foundation courses. 
Course Requirements For MS Degree In Management Information Systems

\begin{tabular}{|l|l|}
\hline Requirements & Semester Credit Hours \\
\hline Skills Development in Computers, Software and & MIS 672 Introduction to C++ or JAVA Programming \\
Business Applications & MIS 674 Data Communications \\
(Total of 9 Cr. Hrs.) & MIS 675 Database Management Systems \\
\hline Skills Development in Supply Chain Applications & MGSC 625 Supply Chain Management \\
(Total of 12 Cr. Hrs.) & MIS 676 Web Development \\
& MIS 677 E-Commerce \\
Skills for System Analysis, Development \& \& $\quad$ MIS 678 SAP Applications in SCM \\
Management(Total of 9 Cr. Hrs.) & MIS 681 IT Project Management \\
\hline Restricted Elective & MIS 685 Management of Information Systems \\
\hline (Total of 3 Cr. Hrs.) & MIS 683 Current topics in MIS or \\
\hline & MIS 684 Internship \\
\hline
\end{tabular}

D. Curriculum

1. Required Courses and Elective.

\begin{tabular}{|c|c|c|}
\hline MGSC 625 & Supply Chain Management & 3 Cr. Hrs. (New) \\
\hline MIS 672 & Introduction to C++ or Java Programming & 3 Cr. Hrs. (New) \\
\hline MIS 674 & Data Communications & 3 Cr. Hrs. (New) \\
\hline MIS 675 & Database Management Systems & 3 Cr. Hrs. (New) \\
\hline MIS 676 & Web Design \& Development & 3 Cr. Hrs. (New) \\
\hline MIS 677 & E- Commerce & 3 Cr. Hrs. (New) \\
\hline MIS 678 & SAP Applications in SCM & 3 Cr. Hrs. (New) \\
\hline MIS 680 & Systems Analysis \& Development \\
\hline MIS 681 & IT project Management & 3 Cr. Hrs. (New) \\
\hline MIS 685 & Management of Information Systems & 3 Cr. Hrs. (New) \\
\hline Elective & $\begin{array}{c}\text { MIS 683 Current Topics in MIS or } \\
\text { MIS 684 Internship in MIS area }\end{array}$ \\
\hline Total & &
\end{tabular}

Course Description:

New courses to be added if the program is approved:

MGSC 625 Supply Chain Management (3)

The course will provide an introduction to Supply Chain Management and the role of information systems in managing supply chains.

(Pre-requisite: MGSC 302)

MIS 672 Introduction to C++ or Java Programming (3)

A review of the programming features of these languages and their application to Object Oriented Programming and development of business applications.

These will be offered in alternate semesters. (Pre-Requisites: MGSC 304). 
MIS 674 Data Communications (3)

Managerial and technological issues related to the operation and maintenance of computer networks. Topics covered include WAN, LAN, Internet and related architectures and protocols. (Pre-requisites: MGSC 304)

MIS 675 Database Management Systems (3)

Database concepts and principles in database design with exposure to a popular relational database like “Oracle.” (Pre-Requisite: MIS 672 or Consent of Instructor)

MIS 676 Web Design \& Development (3)

Web applications and design using tools such as HTML, Cascading Style Sheets, JavaScript and DHTML. (Pre-requisite: MIS 672)

MIS 677 E-Commerce (3)

Provides exposure to the use of Internet for business to business communications, logistics and supply chain management, financial markets, digital payments, marketing etc. (Pre-requisites: MGSC 625, MIS 675,

MIS 678 SAP Applications in SCM (3)

Provides exposure to instructor selected SCM modules in SAP. (Pre-Requisites: MIS 675)

MIS 680 Systems Analysis \& Development (3)

An introduction to concepts and processes for analyzing and determining information requirements and using packages and application generators for system development. (Pre-Requisites: MIS 675, MIS 678)

MIS 681 IT Project Management (3)

Approaches to managing IT projects including outsourcing and subcontracting strategies. Students will also be exposed to project management tools. (Pre-Requisites: MIS 680)

MIS 683 Current Topics in MIS(3)

An instructor selected topic dealing with current issues and/or developments in the MIS area. (Prerequisites: Completion of at least $18 \mathrm{Cr}$. Hrs. of course work in the MIS program)

MIS 684 Internship in MIS area(3)

Student will perform the equivalent of one long semester or an entire summer internship in the Information Technology area in a carefully selected organization.(Pre-requisite: Completion of at least $18 \mathrm{Cr}$. Hrs. of course work in the MIS program.)

MIS 685 Management of Information Systems(3)

Strategic management of information resources to facilitate corporate competitiveness in the global environment. Capstone course to be taken in the student's last semester of the program.

Note: Participation in SAP University Alliance program is also envisaged and discussions have already been initiated with SAP Corpn. 
E. Proposed course scheduling for the first five (5) years of the program:

\begin{tabular}{|l|l|l|l|}
\hline Year & Fall Semester & Spring Semester & Summer \\
\hline 1 & MIS 672, MGSC 625, & MIS 674, MIS 676, & MIS 684 \\
& MIS 675 & MIS 678 & \\
\hline 2 & MIS 672, MGSC 625, & MIS 674, MIS 676 & MIS 684 \\
& MIS 675, MIS 677, & MIS 678, MIS 681 & \\
& MIS 683, MIS 680 & MIS 683, MIS 685 & \\
\hline
\end{tabular}

Note: The year 2 pattern will repeat itself for years 3 through 5 .

\section{Comments}

The proposed curriculum for MS in MIS has been implemented effective fall 2005 at Jesse H. Jones School of Business at Texas Southern University. To support the program three faculty members with good research credentials and Ph.D in the MIS area have been recruited. Required additional hardware and software have been added. About 10 journals in the MIS area have been added to the library holdings. To attract good students research assistantship support has been provided for a few students. About 20 students are currently enrolled in the program. We expect the program to produce graduates with focused skills to perform well in MIS/SCM environment in modern business organizations. The first two gradutes of the program will graduate end of this year and May 2007. They have received good job offers.

\section{REFERENCES}

1. Copra and Meindl Supply Chain Management, Second Edition, Pearson/Prentice Hallyear 2004.

2. Catalogue description of curriculum for a major in Supply Chain Management at the undergraduate level, Michigan University, East Lansing, MI.

3. Van Der Zee, D. J. and Van Der Vorst J. G. A. J. A Modeling Framework for Supply Chain Simulation: Opportunities for Improved Decision Making Decision Sciences, Vol.36, No. 1, Feb. 2005.

4. Vakharia, Asoo J.: e-Business and Supply Chain Management, Decision Sciences, Vol. 33 No.4, Fall 2002.

5. Hausman, Warren, Founder of Supply Chain Seminars and Professor of Management Science and Engineering, Stanford University, from current website advertisement. 
NOTES 